\title{
LA CONSTRUCCIÓN INTELECTUAL DEL CONCEPTO DE COLONIALISMO INTERNO EN AMÉRICA LATINA: DIÁLOGOS ENTRE CARDOSO DE OLIVEIRA, GONZÁLEZ CASANOVA Y STAVENHAGEN $(1959-1965)^{1}$
}

\author{
Breno Bringel ${ }^{1}$ \\ Miguel Leone ${ }^{2}$ \\ ${ }^{1}$ Universidade do Estado do Rio de Janeiro - UERJ, Brasil \\ ${ }^{2}$ Universidad de Buenos Aires - UBA, Argentina
}

Introducción

El colonialismo, entendido como un sistema social, político y económico por el cual un Estado extranjero domina y explota una colonia, es uno de los fenómenos más analizados en la política moderna, debido a sus profundas consecuencias para la formación del capitalismo global y los Estados nacionales. En general, la colonización implica la apropiación de tierra, la expropiación de recursos, la explotación del trabajo, la sumisión de la población y el establecimiento del dominio sobre una unidad política geográficamente externa, habitada por diferentes culturas. Siguiendo esta lógica, el colonialismo se presenta en el imaginario moderno como algo construido de fuera hacia dentro. Esta visión ignora, sin embargo, lo que hace aproximadamente un siglo se empezó a definir como "colonialismo interno". Los orígenes de este término están estrechamente vinculados a los debates políticos del comunismo y del antirracismo llevados a cabo en la Tercera Internacional y en el partido comunista sudafricano en la década de 1920 (Amin, 2009), pero su proliferación posterior se asoció, principalmente, 
a la creación de una gramática común del "tercermundismo" y del "liberacionismo" global en su lucha contra todas las formas de explotación, opresión y dependencia en la década de 1960 (Bringel y Maldonado, 2016: 402-408; Valdés, 2003).

La genealogía de este término es múltiple y estuvo muy asociada a movimientos sociales y políticos concretos, extendiéndose de formas diversas -y no siempre conocidas o conectadas- en el Sur y en el Norte Global. En África, resultó útil para interpretar las lógicas de dominación ejercida por las élites internas tras las luchas por las independencias. Y, antes de eso, las luchas por la liberación negra contra el racismo y la segregación racial, teniendo a Sudáfrica como caso emblemático, inicialmente en las resistencias de trabajadores negros en la búsqueda de una "República Nativa" y luego ante el apartheid (Adam, 1972; Carter, Karis y Stultz, 1967). Bajo el eco de estas inspiraciones, activistas e intelectuales negros postularon la hipótesis de que la población racializada en los Estados Unidos formarían una "colonia interna" dentro de las fronteras de la "patria imperial" (Haywood, 1948). Con el paso del tiempo, los guetos se convirtieron en el ejemplo habitual (Cruser, 1968; Blauner, 1969) y la tesis del colonialismo interno aparecería en los discursos de Malcolm X e incluso en el programa político del Black Panther Party (Allen, 2015).

En Europa, motor de propulsión del colonialismo globalmente, el debate sobre el colonialismo interno apareció de una manera distinta, principalmente a través de reclamos políticos por la autodeterminación de naciones sin un Estado propio, que se sienten subyugadas, oprimidas y/o no reconocidas dentro de territorios definidos por Estados ajenos, pero a los que tienen que responder formalmente. Son muchos los casos históricos y actuales en Europa, pero también de "nacionalismos periféricos" en la periferia mundial, donde los pueblos originarios y las poblaciones de las naciones sin Estado están mucho más privadas de libertades civiles y políticas, además de excluidas y subalternizadas, que aquellas naciones sin Estado del centro sistémico (Hechter, 1975).

Además, la noción de colonialismo interno permitió interpretar relaciones coloniales al interior de países diversos y complejos como Israel, Tailandia, Pakistán, Groenlandia, Canadá o los territorios de la antigua Unión Soviética (Torres Guillén 2017: 2; Hicks 2004). A pesar de las diferencias entre estos casos y sus implicaciones (geo)políticas, todas estas lecturas reivindican que el colonialismo no es sólo un fenómeno "internacional", sino también "intra-nacional", con potencial explicativo para comprender las formas de dominación y explotación. 
Más allá de los usos políticos preexistentes del término, buena parte de la literatura internacional suele referirse a González Casanova como uno de los precursores en el tratamiento conceptual más sofisticado de la noción de colonialismo interno (Burawoy, 1974)². Lo curioso es que uno de los textos más citados del autor sobre el tema, que suele ser mencionado como un "trabajo pionero" (González Casanova, 1965a), no es el primer artículo del mexicano sobre la cuestión. Sin embargo, está escrito en inglés y por esta razón circuló mucho más ampliamente fuera de América Latina que su artículo original y seminal publicado dos años antes en español (González Casanova, 1963a). A su vez, en el ámbito latinoamericano frecuentemente se reconoce a La democracia en México y a Sociología de la Explotación como los trabajos en los que González Casanova (1965b; 1969) sistematizó el concepto de colonialismo interno. En este caso, la centralidad adquirida por esos dos libros a lo largo del tiempo acabó contribuyendo a nublar los debates previos y las publicaciones en artículos del propio autor y de sus interlocutores más cercanos ${ }^{3}$. En esta trama, en la que convergen los intentos de construcción de un pensamiento social propio, la dependencia académica, la división intelectual del trabajo científico, la centralidad del libro en las ciencias sociales y las asimetrías en la circulación de ideas (Beigel, 2016; Bringel y Domingues, 2015; Silva, 2019), hay algo que se suele ocultar: la construcción del debate latinoamericano sobre el colonialismo interno no se dio solo por la creatividad de un intelectual tan central y fecundo como González Casanova, sino que fue fruto de un proceso colectivo de colaboraciones e intercambios de ideas, inquietudes e investigaciones.

En el presente texto argumentamos que el debate académico sobre el colonialismo interno en América Latina es tributario de los diálogos seminales que se establecieron entre los mexicanos Pablo González Casanova y Rodolfo Stavenhagen y el brasileño Roberto Cardoso de Oliveira durante finales de los años 1950 y la primera mitad de la década de 1960. Aunque cada uno de estos intelectuales partían de trayectorias, experiencias y puntos de vistas diferentes, fue crucial la participación activa de todos ellos en el Centro Latinoamericano de Pesquisas en Ciencias Sociales (en adelante, CLAPCS o "Centro"), institución creada por la UNESCO en 1957, con sede en Río de Janeiro, que sirvió como el principal espacio de acogida de los diálogos e investigaciones sobre el tema. Las investigaciones y seminarios del Centro fueron clave para el desarrollo del concepto, cuyo debate se publicó en su revista América Latina, difundiéndolos más ampliamente para el público de la región o a los interesados en América Latina. El objetivo del artículo es reconstruir estos diálogos entre Cardoso de Oliveira, González Casanova y Stavenhagen alrededor del CLAPCS. Nuestra búsqueda no 
tiene como horizonte construir una historia intelectual del concepto de colonialismo interno en los moldes sugeridos por Koselleck (2002). En vez de restringirnos al lenguaje y a la semántica, exploraremos principalmente cómo el contexto y el intercambio de experiencias han sido fundamentales para la (re)elaboración de dicha noción. Trataremos de demostrar que la construcción del concepto de colonialismo interno fue indisociable tanto de la circulación transnacional de intelectuales propiciada por el Centro como de su dinámica interdisciplinaria.

El artículo está dividido en cinco partes, además de la presente introducción y una conclusión. La primera parte presenta el CLAPCS como un espacio de convergencia transnacional de intelectuales, subrayando sus actividades y repercusiones en términos de circulación de ideas y personas. A continuación, se introducen los debates iniciales sobre el concepto de colonialismo interno, sus principales influencias e intercambios fundacionales. En la tercera parte se discuten los lineamientos que González Casanova dio al concepto para, en seguida, examinar los avances de la antropología social, a través de las elaboraciones de Cardoso de Oliveira y de Stavenhagen. En la última parte, recuperamos algunas reelaboraciones críticas y ecos del debate en desarrollos posteriores.

El nuestro es, por lo tanto, un esfuerzo similar, aunque más amplio, al realizado por Gandarilla (2018), que si bien reconoce la centralidad de las redes del CLAPCS y el carácter colectivo de la gestación del concepto de colonialismo interno, se centra fundamentalmente en los aportes de González Casanova. Para llevar a cabo tal tarea, se han utilizado fuentes mixtas. Para la reconstrucción del espacio social del CLAPCS, así como la inserción de Cardoso de Oliveira, González Casanova y Stavenhagen en la institución, utilizamos las siguientes fuentes: a) registros de las reuniones del Comité Directivo CLAPCS-FLACSO; b) informes sobre la participación de los tres intelectuales en el Centro; c) plan de actividades del CLAPCS entre 1957 y 1965; d) entrevistas a González Casanova y Stavenhagen, bien como a otros intelectuales que participaron del CLAPCS o colaboraron con el Centro. Por otro lado, para profundizar en el debate sobre el colonialismo interno, se suman a las fuentes anteriores de carácter más biográfico, contextual, histórico, institucional e intelectual, otras de carácter textual que permiten entrever los avances de la discusión en los artículos, debates e investigaciones del CLAPCS. Para tal fin, utilizamos números diversos de dos publicaciones editadas por el Centro -el Boletín y la revista América Latina-, bien como avances y resultados de investigaciones y libros vinculados al tema, además de fuentes secundarias relevantes. 


\section{EI CLAPCS como espacio de convergencia transnacional de las ciencias sociales}

Tras tres años de intensas negociaciones y encuentros, la $2^{\circ}$ Conferencia Regional de Ciencias Sociales para América Latina, realizada en abril de 1957, crea el CLAPCS como un centro de investigación radicado en Rio de Janeiro, y la Facultad Latinoamericana de Ciencias Sociales (FLACSO), dedicada a la enseñanza y radicada en Santiago de Chile. Poco más de un mes después, un decreto del presidente brasileño Juscelino Kubitschek dio nacimiento formal al Centro. El CLAPCS y la FLACSO compartieron un mismo Comité Directivo (CD), responsable por deliberar sobre el rumbo de ambas instituciones (Beigel, 2009). Sus miembros, elegidos en principio por cuatro años aunque algunos cumplieron más de un período, fueron importantes artífices de la institucionalización de las ciencias sociales en sus respectivos países ${ }^{4}$. Entre ellos elegían un presidente, cuya gestión duraba dos años. Pablo González Casanova, quien ingresó en el Comité en 1959, fue su presidente en dos ocasiones, en los bienios 1961-1962 y 1965-1966.

Además de este CD compartido, el CLAPCS tenía su propio director y un Secretario General. El primer director fue el sociólogo brasileño Luiz de Aguiar Costa Pinto, quien cumplió un mandato de cuatro años (19571961), siendo reemplazado por el antropólogo Manuel Diégues Junior, al frente del Centro durante toda la década de 1960 y parte de los 1970. Ambos mantuvieron relaciones muy cercanas con los miembros del CD, quienes tenían que aprobar los informes y planes de trabajo. Además, participaban activamente en la vida intelectual del CLAPCS, organizando eventos, coordinando investigaciones, contribuyendo con publicaciones y dinamizando, en sus respectivos países, varias actividades. El director era una figura crucial en las tareas organizativas y en el liderazgo científico y político del proyecto. Era apoyado por el Secretario General, que también tenía un papel importante en la coordinación de las actividades científicas y administrativas del Centro. Rodolfo Stavenhagen fue el Secretario General entre agosto de 1962 y diciembre de 1964, periodo en el cual vivió en Río de Janeiro, participando del día a día de la vida del CLAPCS y contribuyendo a su conducción junto a Diégues Jr. Lo sucedió el haitiano Jean Casimir, quien ocupó el cargo hasta principios de 1968, año en el que la UNESCO retiró el apoyo financiero al Centro y la dictadura en Brasil se recrudeció. Al año siguiente, en 1969, el CD conjunto fue disuelto y el CLAPCS empezó a perder sus principales bases de sustentación internacional en un momento de profunda inestabilidad política en la región. El CLAPCS entró así en un 
período de mayor repliegue local/nacional de sus actividades y cerró sus puertas diez años después, en 1979, tras una larga crisis.

A pesar de esta trayectoria intermitente, la primera década del CLAPCS fue un periodo muy fértil e intenso, que lo ubicó, en tanto institución, como uno de los principales vectores de la circulación transnacional de intelectuales en un momento clave de institucionalización de las ciencias sociales en la región. De hecho, desde sus orígenes, el Centro se esforzó por vincularse con espacios de investigación y enseñanza de toda la región. Entre varias otras apuestas fue, por ejemplo, un impulsor decisivo para la creación en 1967 del Consejo Latinoamericano de Ciencias Sociales (CLACSO), hoy la principal institución en la vertebración de las ciencias sociales en América Latina ${ }^{5}$.

En lo que se refiere a las investigaciones, el CLAPCS llevó a cabo más de treinta proyectos sólo en su primera década. Lo que más llama la atención de las investigaciones es la apuesta decisiva por una perspectiva latinoamericana a partir de un abordaje empíricamente orientado a cuestiones macrosociales (urbanización, industrialización, estructura agraria, desarrollo económico y estratificación social) y a los conflictos societales e impactos derivados del proceso modernizador y del desarrollo. También había un afán por organizar la bibliografía existente sobre estos temas, bien como generar estudios sobre las propias ciencias sociales en los diferentes países. Buena parte de las investigaciones involucraba equipos multinacionales que trabajaban conjuntamente, mirando tanto a los aspectos comunes como a las especificidades de los lugares y países. Investigadores de Argentina, Brasil, Chile, Colombia, Costa Rica, México, Uruguay y Venezuela estuvieron especialmente comprometidos en los proyectos, que resultaron en diversos tipos de eventos y seminarios y en publicaciones conjuntas de alcance regional. En su primera década, el CLAPCS organizó quince seminarios de considerable envergadura, entre los cuales se incluyen el I Seminario Latinoamericano de Estratificación y Movilidad Social (1958), el Seminario Internacional "Resistências à Mudança" (1959), la Conferencia Internacional sobre Investigación Comparativa (1964), el Seminario Ciencias Sociales en América Latina (1965) y el Seminario sobre Sociología del Desarrollo (1968).

Estos seminarios y las investigaciones que les dieron origen, unida a la propia estructura institucional del CLAPCS, posibilitaron generar un singular espacio de encuentro entre los principales referentes de las ciencias sociales latinoamericanas. La circulación en la sede del Centro, en sus actividades cotidianas y en sus eventos, no se restringió, sin embargo, a la intelectualidad de la región, sino que se promovió también un fuerte intercambio con instituciones y referentes del Norte. Estuvieron en el Centro, en misiones de 
corto o medio plazo, intelectuales como Alain Touraine, Charles Wright Mills, Joseph Kahl o Herbert Blumer, entre muchos otros. Los últimos dos nombres llegaron al Centro como peritos (experts) de la UNESCO, involucrándose en diversas actividades del CLAPCS. ${ }^{6}$

Herbert Blumer fue el primer expert de la UNESCO en el CLAPCS. Cuando llegó a Río de Janeiro en agosto de 1958 ya tenía una carrera consolidada. Había sido presidente de la American Sociological Association y ocupado el puesto de editor del American Journal of Sociology por más de una década (1941-1952). Ya tenía una vasta experiencia en la Universidad de Chicago, donde actuó entre 1927 y 1952, año en el que se mudó a Berkeley para fundar el Departamento de Sociología de la Universidad de California. Su contribución sobre el interaccionismo simbólico y los métodos de investigación en ciencias sociales fue muy influyente y dejó huellas importantes en el Centro, donde su misión inicial fue coordinar una investigación sobre las implicaciones sociales de la industrialización en el Recóncavo, en Bahía (Boletín del CLAPCS, 1958, n.2: 3)7. Asimismo, Blumer participó de numerosas actividades del Centro y coordinó un estudio teórico-metodológico sobre urbanización e industrialización, cuyo objetivo era analizar la discusión existente sobre el tema, tratando de armar un "esquema conceptual y directrices metodológicas que contribuyan a disipar la gran confusión de ideas y conceptos existente en la bibliografía" (Boletín del CLAPCS, 1959, n.2: 8-9; Blumer, 1959).

Blumer regresó a Estados Unidos en octubre de 1959 y unos meses después llegó al CLAPCS Joseph Kahl, quien se quedó en Río de Janeiro hasta principios de 1961. Bajo su coordinación estuvo el proyecto "Orientación de las Carreras Ocupacionales vinculadas al Desarrollo Económico", que buscaba investigar los aspectos psicosociales del cambio social (Boletín del CLAPCS, 1960, n.3: 88-91), desde una perspectiva muy marcada por las teorías de la modernización (Kahl, 1962). Una de sus principales contribuciones fueron sus aportes metodológicos y sus estudios sobre estratificación social. Pocos años antes de llegar a Río de Janeiro, había publicado The American Class Structure (Kahl, 1957), considerado un libro fundante sobre el tema, responsable por contribuir a delimitar este campo de estudios. Se trató, por cierto, de un tema central en la agenda del CLAPCS, en el cual fue pionero en Brasil, ya que los primeros estudios sistemáticos sobre estratificación social en este país están asociados a los peritos enviados por la UNESCO, principalmente Bertram Hutchinson, Sugiyama Yutaka y el propio Kahl (Aguiar, 2001). A diferencia de Blumer, Kahl tenía un interés especial por América Latina. Su libro sobre estratificación en Estados Unidos había sido escrito en México, cuando él era estudiante de doctorado y se 
entusiasmó con la región. Allí conoció a Pablo González Casanova, sobre quien escribió un libro, a finales de los 1970, comparando sus contribuciones a las de otros dos autores que también conocía bastante bien: Gino Germani y Fernando Henrique Cardoso (Kahl, 1976).

La experiencia de Kahl en Río de Janeiro se unió a las marcas de su experiencia mexicana y desde entonces se convirtió en Estados Unidos en un gran divulgador de las ideas producidas en América Latina ${ }^{8}$. Además, recibió en su país natal a diversos investigadores latinoamericanos. Este fue el caso de Glaucio Soares, con quien entabló una estrecha relación en el año que estuvo en Río de Janeiro. De ahí que Soares hiciera con Kahl, entre 1962 y 1965, su tesis doctoral, previo paso en México, recomendado por su futuro director de tesis, para dictar un curso de métodos en el Museo Nacional de Antropología e Historia de México (Brasil Jr., 2013: 98). Allí Soares, antes de embarcar para su estancia en Estados Unidos, pudo conocer a González Casanova y profundizar su interés por América Latina, algo que vivió con mayor intensidad tras terminar su doctorado y asumir la dirección de la Escuela de Sociología de la FLACSO en Santiago de Chile (Castro Gomes y Araujo, 2008).

En lo que se refiere a los nombres antes citados que colaboraron más puntualmente, Alain Touraine tuvo su carrera en América Latina construida por otras vías, no siendo el CLAPCS algo realmente importante en su trayectoria, por más que haya acudido a actividades del Centro varias veces entre 1959 y 1964. Sin embargo, en el caso de Wright Mills, aunque su colaboración también fue tópica, el derrotero fue distinto. Su participación en un seminario del Centro en 1959 resultó, como veremos, de un estímulo vital para la construcción del concepto de colonialismo interno.

En el marco de esta intensa dinámica de investigación y circulación, la relación que González Casanova y Stavenhagen mantuvieron con el CLAPCS estuvo lejos de ser episódica. Como ya se ha mencionado, ambos ocuparon puestos relevantes de dirección que indican un vínculo orgánico con el Centro, motivo por el cual resulta llamativo que la bibliografía referida a sus aportes y trayectorias se detenga relativamente poco sobre sus relaciones con Brasil y sobre los lazos estrechos que mantuvieron con el CLAPCS entre finales de la década de 1950 y mediados de 1960.

Es sabido, no obstante, que Pablo González Casanova y Rodolfo Stavenhagen fueron artífices centrales de la institucionalización de la sociología en México y en América Latina (De la Garza, 2015). Ambos cumplieron roles de liderazgo intelectual (Jackson y Blanco 2016; Zapata, 1981) y son recordados no solamente por sus contribuciones substantivas (Zapata 1995), sino también por haber ocupado puestos destacados dentro y 
fuera de la academia. En el caso de González Casanova, ejerció la dirección de la Facultad de Ciencias Políticas y Sociología (1957-1965) y del Instituto de Investigaciones Sociales (1966-1970) de la UNAM, la rectoría de la UNAM (1970-1972), la presidencia de la Asociación Latinoamericana de Sociología - ALAS (1968-1972 y 1983-1985) y el cargo de consejero de la Universidad de las Naciones Unidas (1982-1988), entre otros.

En el caso de Stavenhagen, se suele destacar su liderazgo institucional a partir de los años 1970, en la fundación y dirección inicial del Centro de Estudios Sociológicos -CES/COLMEX (1973-1976), su rol fundamental en la creación en 1975 de la FLACSO México, su participación en la Secretaría de Educación Pública de México como director general de las Culturas Populares (1977-1979) o su actuación como subdirector general de la UNESCO -responsable por la división de Ciencias Sociales (1979-1982)- y, posteriormente, en el inicio de este nuevo siglo, como relator especial para los Derechos Humanos de los Pueblos Indígenas por las Naciones Unidas.

Nacido en 1922, González Casanova es diez años más mayor que Stavenhagen, de quien fue profesor en la década de 1950, invitándole a incorporarse como docente en la UNAM años después. Los dos se vincularon al CLAPCS en momentos y de formas diferentes. González Casanova lo hizo de la mano del gran impulsor de la institucionalización de la sociología mexicana, Lucio Mendieta y Nuñez (Serrano, 2016), en octubre de 1959 en la III Reunión del CD, realizada en Río de Janeiro. A su vez, Stavenhagen se incorporó al CLAPCS de la mano del entonces presidente del CD, su compatriota González Casanova, en agosto de 1962 en la VI Reunión del CD, realizada en Ciudad de México. Cada uno a su manera, contribuyeron de manera decisiva a forjar diálogos latinoamericanos y a moldar conceptualmente la noción de colonialismo interno.

\section{Inspiraciones e intercambios iniciales: sociedad dual y trabas al desarrollo}

Los primeros pasos del CLAPCS se dieron en un momento de total vigencia de la teoría de la modernización, representada de forma más sofisticada en la región por la sociología de Gino Germani (Domingues y Maneiro, 2004). A pesar de eso, el estructuralismo cepalino, y especialmente los aportes de Prebisch y Furtado sobre las relaciones entre el centro y la periferia en la economía internacional, también marcaban la sociología latinoamericana en un momento en el que era muy extendida la discusión sobre las "sociedades subdesarrolladas" como "sociedades duales". Según 
Frank (1972), fueron las ideas de J.H. Boeke sobre la sociedad indonesia las primeras que plantearon, a comienzos de la década de 1940, el problema de las asimetrías en el desarrollo capitalista que ciertos sectores de la economía nacional podían presentar frente a procesos acelerados de crecimiento económico e industrial (Torres Guillén, 2012). En el mismo período, Many Mexicos, de Lesley Byrd Simpson, y un poco más tarde, Os dois Brasis, de Jacques Lambert, constituyeron un tipo de abordaje más sistemático sobre tales cuestiones.

Formando parte de ese campo de debates, la cuestión de las "sociedades duales" era una temática recurrente en el CLAPCS. Fue un elemento central del Seminario "Resistência à Mudança: Fatores que impedem ou dificultam o Desenvolvimento", organizado por el CLAPCS en 1959. Se trató de una actividad reiteradamente recuperada por las memorias del Centro, bien como por los participantes e interesados en el tema (Ferreira, 1999). Eso porque al seminario, que tuvo amplio eco público, asistieron cerca de 60 investigadores de diversos países (Boletín del CLAPCS, 1959: 16). Destacaron las presencias de Jacques Lambert, Jean Labbens, Roger Sèguin, C. Wright Mills, Alfred Metraux y Gino Germani, en diálogo con importantes intelectuales brasileños como Milton Santos, Thales de Azevedo, Florestan Fernandes, Juarez Brandão Lopes, Fernando Henrique Cardoso y Octavio Ianni, entre otros.

El trabajo presentado por Jacques Lambert sirvió como una especie de ponencia marco y se tituló "Los obstáculos al desarrollo provenientes de la formación de una sociedad dualista". A su vez, la ponencia de Wright Mills, "Remarks on the problems of industrial development", se convirtió en una de las más atendidas. En varias oportunidades, González Casanova ha señalado que fue allí cuando escuchó por primera vez la expresión de "colonialismo interno" (Torres Guillén 2012). Lo que Mills dijo entonces, recuperando la ponencia previa de Lambert, fue que:

Las secciones desarrolladas dentro del mundo subdesarrollado -en las capitales y en los márgenes-son una curiosa forma de poder imperialista, poseyendo algo así como colonias internas. Algunas veces ellas son Estados pero no realmente naciones, y los estados que ellas dominan frecuentemente son parásitos en la economía local, antes que instrumentos para crear una nueva economía (Wright Mills, 1960: 285).

Pero si bien fue Wright Mills quien inspiró a González Casanova, fue el intelectual mexicano quien "lo convirtió en un concepto analítico" (Torres Guillén, 2017: 1) ubicándolo en el debate académico regional e internacional. ${ }^{9}$ Eso no implica que haya sido el primero en utilizar el término ni tampoco que haya desconocido las raíces marxistas del debate, por más 
que algunas genealogías importantes previas hayan sido obviadas por el intelectual mexicano. De hecho, González Casanova (2006) reconoce en Lenin un punto de partida crucial, principalmente en su trabajo clásico en el que argumenta que un país imperialista exportaba la explotación del proletariado a sus colonias o a otros países subdesarrollados cuyos términos de intercambio podía controlar (Lenin, 1952 [1916]). Otra contribución fundamental tiene que ver con el rol de las "minorías nacionales" en los Estados y la necesidad de denunciar las violaciones de la igualdad nacional.

Las contribuciones de Lenin deben ser leídas dentro de los debates de la izquierda internacionalista de aquel momento. Tras la Revolución Rusa de 1917, la recién creada Internacional Comunista dedicó sus esfuerzos a conocer la lucha anticolonial de los pueblos no occidentales y convocó una reunión para ello: el Congreso de los Pueblos del Este, celebrado en 1920 en Baku, Azerbaiyán. Allí se llevaron a cabo las primeras discusiones amplias sobre el marxismo y la cuestión colonial (Broué, 1977) y se generó un contexto fundamental para el fortalecimiento de una "tradición negra radical" (Robinson, 1983) que pasó a interpelar el colonialismo (interno y externo), el racismo y la superexplotación capitalista.

En este mismo momento político, aunque en otro contexto, Gramsci intentó explicar en sus Quaderni del carcere escritos entre 1929 y 1935, cómo en el caso italiano, solo podíamos entender la miseria del Mezzogiorno a partir de la dominación y la riqueza del Norte. En palabras del propio Gramsci, el Norte era una especie de "sanguijuela" que se enriqueció a costa del Sur. Habría que agregar también la influencia en González Casanova de las contribuciones de Mariátegui respecto del lugar de los pueblos originarios y los ecos de sus conocidas polémicas con Haya de la Torre, que derivaron en una fuente de inspiración ineludible de crítica a las perspectivas modernizadoras. Igualmente, las ideas de Henri Lefebvre y Nicos Poulantzas sobre la ocupación y la reestructuración del espacio y del poder en el capitalismo fueron cruciales (González Casanova, 2006).

Estas contribuciones intelectuales y políticas fueron fundamentales para visibilizar las relaciones centro-periferia no sólo entre Estados, sino también en el interior de un país, una sociedad o una región. Es así como la noción de colonialismo interno propuso un abordaje sobre este tipo de relaciones de dominación, superando una visión de exterioridad, impactando en las explicaciones estructurales e históricamente fundamentadas sobre la condición de "dualidad" de estas sociedades. Habría que ubicar estas influencias marxistas de González Casanova y la coexistencia con el funcionalismo y el desarrollismo modernizador muy presente en el CLAPCS y en el debate de la época, con un proceso progresivo de "transición" del 
debate intelectual y político latinoamericano. Por un lado, el pensamiento de izquierdas por entonces se renueva, criticando las lecturas previas más mecánicas del marxismo. Por otro, entre la Revolución Cubana de 1959 y el golpe de 1964 en Brasil se produjo, como sugiere Zapata (1990: 217), un desplazamiento paulatino "entre la industrialización sustitutiva y un nuevo modelo de dominación política en el que los militares empezaron a desempeñar un papel distinto al que habían jugado hasta entonces".

Esto fue llevando, a principio de los años 1960, a la emergencia de perspectivas más críticas sobre el desarrollo, que cuestionaban las miradas dicotómicas y etapistas (Bringel y Echart, 2017). Una de estas vías explicativas se dio a partir del concepto de marginalidad a través del cual solía relucir una "sociedad participante" y una "sociedad de masas marginales" (Cortes, 2018). El debate sobre la marginalidad es muy amplio y transitó por itinerarios bastante diferentes: desde su uso social o cultural inicialmente asociado a inicios de los 1960 a los procesos de modernización, hasta llegar a formulaciones más críticas años después con Aníbal Quijano, José Nun, Fernando Henrique Cardoso, Luiz Antonio Machado da Silva, Lúcio Kowarick y otros.

Uno de los avances principales de las teorías más significativas de la marginalidad fue superar la visión que separaba un sector integrado de otro marginal para incorporar una concepción relacional, en la cual habrían diferentes tipos de relaciones y niveles de dominación. Institucionalmente, muchos de estos debates fueron sostenidos, a nivel latinoamericano, con el auspicio de la Fundación Ford, destacándose el papel del Centro de Investigaciones Sociales del Instituto Torcuato Di Tella en Buenos Aires, el Instituto Latinoamericano de Planificación Económica y Social (ILPES) y el Centro para el Desarrollo Social para América Latina (DESAL), con sede en Santiago de Chile. Se podría decir que, de forma paralela, otra vía de cuestionamiento de las sociedades duales fue el debate sobre el colonialismo interno que pasaremos a reconstruir en las siguientes secciones. En este caso, el principal paraguas institucional fue el CLAPCS.

\section{El colonialismo interno en Pablo González Casanova}

Tras la realización del Seminario Resistencias à Mudança, González Casanova empezó a trabajar en sus primeras formulaciones sobre el colonialismo interno. Su admiración por Mills se tornó mucho más amplia que el "préstamo" de esta idea, compartiendo con éste el cultivo de una "imaginación sociológica" creativa y heterodoxa (Torres Guillén, 2017). En 
este proceso, González Casanova construyó su propia interpretación del tema, cuyo primer germen está en su texto "Sociedad plural y desarrollo. El caso de México", publicado en 1962 en la Revista América Latina del CLAPCS. Movilizando datos empíricos sobre alimentación, consumo de bienes básicos y analfabetismo, González Casanova demostró que, aun cuando la marginalidad había disminuido en términos relativos durante las primeras décadas posteriores a la Revolución Mexicana, sus valores absolutos habían aumentado, manteniendo incluso una tendencia creciente (González Casanova, 1962). En virtud de ello, González Casanova concluía que "la sociedad plural", característica de los países coloniales y subdesarrollados,

puede subsistir en períodos relativamente largos en países que han logrado una relativa independencia política y económica, que han hecho una reforma agraria, que han iniciado el proceso de capitalización, industrialización y urbanización característicos del desarrollo (González Casanova, 1962: 41).

A continuación, publicó en la revista Desarrollo Económico, editada por el Instituto de Desarrollo Económico y Social (IDES) de Buenos Aires, un artículo en el que se pregunta sobre "el dominio de los grupos y clases más poderosas en el interior de la nación sobre los grupos y clases menos poderosas y marginales" (González Casanova, 1963a: 285). Este mismo año apareció, otra vez en la revista del CLAPCS, el artículo "Sociedad plural, colonialismo interno y desarrollo", que puede ser considerado el texto fundacional del debate académico en la región. Es ahí donde González Casanova (1963b) aborda explícitamente el "colonialismo interno", tratando de buscar una definición estructural que "pudiera servir para [producir] una explicación sociológica del desarrollo" (González Casanova, 1963b: 17), y de "los problemas de las sociedades subdesarrolladas" (González Casanova, 1963b: 18). Es así como el concepto de colonialismo emerge como una interpelación sobre la condición estructural de las "sociedades duales":

al lograr su independencia las antiguas colonias (...) conservan, sobre todo, el carácter dual de la sociedad y un tipo de relaciones similares a las de la sociedad colonial, que ameritan un estudio objetivo y sistemático (González Casanova, 1963b: 24-25).

A continuación, postula una definición del concepto que, con pocas variaciones, persistiría como tal hasta la actualidad: 
[colonialismo interno es] una estructura de relaciones sociales de dominio y explotación entre grupos culturales heterogéneos, distintos. Si alguna diferencia específica tiene respecto de otras relaciones de dominio y explotación (ciudad/ campo, clases sociales) es la heterogeneidad cultural que históricamente produce la conquista de unos pueblos por otros, y que permite hablar no sólo de diferencias culturales (que existen entre la población urbana y rural y en las clases sociales) sino de diferencias de civilización (...) La estructura colonial y el colonialismo interno se distinguen de la estructura de clases, porque no es sólo una relación de dominio y explotación de los trabajadores por los propietarios de los bienes de producción y sus colaboradores, sino una relación de dominio y explotación de una población (con sus distintas clases, propietarios y trabajadores) por otra población que también tiene distintas clases (propietarios y trabajadores) (González Casanova, 1963b: 25-26).

Desde entonces, la heterogeneidad cultural y estructural, las múltiples relaciones de dominio y explotación y la estructura colonial se convirtieron en elementos clave de una noción que se va sedimentando en el pensamiento de González Casanova a partir de la confluencia entre su proceso como investigador en diferentes escuelas e institutos de la UNAM (Torres Guillén, 2012; Gandarilla, 2018) y sus intercambios con otros intelectuales latinoamericanos y del mundo que buscaban una mirada crítica sobre el desarrollo. Su inserción en el CLAPCS le permitió no sólo participar de eventos relevantes como el Seminario Resistências à Mudança, sino también acceder de forma privilegiada a un debate latinoamericano e internacional y conocer, de manera cercana, conversaciones que su compatriota Stavenhagen empezaba a mantener con el antropólogo brasileño Cardoso de Oliveira. Asimismo, el hecho de que eligiera la revista América Latina para publicar sus artículos sobre el tema no fue una mera casualidad. Stavenhagen ya era el Secretario General del CLAPCS y una de sus misiones era fortalecer las publicaciones del Centro. El mismo González Casanova relató que los editores de la revista América Latina originalmente programaban publicar un texto de Stavanhagen a inicios de 1963 que también hacía uso del concepto de colonialismo interno y que, sin embargo, el propio Stavenhagen decidió posponer la publicación de su artículo para el siguiente número, abriendo espacio para el artículo de González Casanova ${ }^{10}$.

Durante este proceso, González Casanova estaba inmerso en un proyecto ambicioso que luego se convertiría en La democracia en México. El libro, publicado en 1965, presenta un lúcido análisis crítico del sistema político posrevolucionario mexicano (Jackson y Blanco, 2016) y también integra elaboraciones presentadas por el autor en los dos citados artículos 
de la revista América Latina. Es, precisamente, en aquellas elaboraciones en donde el autor encontró las soluciones posibles a las fallas detectadas en la relación entre la estructura social y la estructura política mexicana. Pues, a su juicio, la división del país en dos o más mundos, con características distintas, tiene que ver con un fenómeno más profundo, que es el colonialismo interno, o el dominio y explotación de unos grupos culturales por otros (1967: 89).

Si bien el vínculo de González Casanova con el CLAPCS fue estrecho en términos institucionales e intelectuales, el sociólogo mexicano nunca pasó periodos prolongados en Río de Janeiro. A la vez que integraba formalmente los cuadros políticos del CLAPCS, contribuía fuertemente en México a la implantación de una nueva cultura intelectual, conduciendo procesos de modernización disciplinaria en las ciencias sociales de su país. Desde allí, buscó explorar la riqueza heurística de la noción de colonialismo interno, ya que como subrayó en su artículo de 1963, la categoría precisaba de "un estudio analítico y objetivo" para poder captar toda "su riqueza explicativa y práctica" (González Casanova, 1963b: 27).

Fue eso lo que intentó hacer en el libro Sociología de la explotación, donde sistematizó los mecanismos de transferencias de excedente y analizó el colonialismo interno como una forma de explotación ("por regiones") capaz de conjugarse con la explotación de clase (González Casanova, 1969). Unido a eso, siguió analizando la importancia de entender cómo la variable étnica operaba en esas formas de explotación y dominación. En La democracia en México fue rotundo al decir que "el problema indígena es esencialmente un problema de colonialismo interno. Las comunidades indígenas son nuestras colonias internas" (González Casanova, 1965b: 104). O también: "el colonialismo interno existe donde quiera que hayan comunidades indígenas" (González Casanova, 1965b: 105). Aun así, no fue González Casanova quien más se ocupó en trabajar esta dimensión del concepto.

\section{Colonialismo interno, etnicidad y fricción interétnica: los aportes de Cardoso de Oliveira y de Stavenhagen}

El espacio de intercambio académico del CLAPCS cobijó debates sobre la etnicidad desde sus inicios. En el comienzo, como era habitual, lo hizo bajo lo que se entendía entonces como el problema de la "asimilación" de "las poblaciones indígenas", los campesinos y las comunidades rurales; todas ellas entendidas, a su vez, como "populações atrasadas" y "fatores de resistência à mudança social" (Boletín del CLAPCS, 1959, n.4: 16). No obstante, aún desde esos cuestionables anclajes políticos e ideológicos, 
lo que se solía definir como "sociología del desarrollo" resultó ser un campo muy permeable al "problema de la etnicidad". Los debates que Cardoso de Oliveira y Stavenhagen llevaron adelante en ese campo no tardaron en dar una respuesta crítica a esa perspectiva del "desarrollo".

El artículo cuya publicación Stavenhagen decidió posponer para dar lugar al texto de González Casanova se tituló "Clases, colonialismo y aculturación. Ensayo sobre un sistema de relaciones interétnicas" y formó parte del cuarto número de la revista América Latina, también publicado en 1963. Allí Stavenhagen recuperó el concepto de colonialismo interno, sobre el cual venía igualmente trabajando desde su llegada a Río de Janeiro un año antes, y buscó ponerlo en diálogo más estrecho con la cuestión de la etnicidad, problematizándolo a partir de datos empíricos emergentes en sus propias investigaciones. El objetivo del texto era "reorganizar los datos conocidos [sobre las relaciones interétnicas en las regiones interculturales de los altos de Chiapas y Guatemala] en un esquema de interpretación que difiere de los esquemas comunes en la antropología" (Stavenhagen, 1963: 64). El artículo planteó que el "análisis de clases" resulta "más adecuado para comprender las relaciones entre economía y sociedad" y el lugar que las etnicidades juegan allí (1963: 63). En esa línea, Stavenhagen observó críticamente:

La importancia que los etnólogos han atribuido a los elementos culturales de las poblaciones indígenas ha disimulado durante mucho tiempo la naturaleza de las estructuras socio-económicas en las que están integradas dichas poblaciones (Stavenhagen, 1963: 65).

Stavenhagen (1963: 100) subrayaba que "el carácter clasista y el carácter colonial de las relaciones interétnicas son dos aspectos íntimamente ligados de un mismo fenómeno" y proponía leer las relaciones interétnicas, entre indígenas y ladinos, como "un conjunto complejo e integrado" (1963: 65), es decir, como "un sistema de relaciones" (1963: 89) que conforma una misma estructura de clases en la que ambos sectores mantienen entre sí relaciones de dominación y conflicto.

No es posible entender esta lectura de Stavenhagen sin entender su propia trayectoria intelectual. Como señalan Oto y Catelli (2018: 14), el lugar que la antropología y las preguntas sobre los pueblos originarios ocuparon en su formación le llevaron a inquietarse particularmente por la dimensión étnica del colonialismo interno. Stavenhagen se había graduado en Antropología en 1951, en la Universidad de Chicago, habiendo sido alumno de Robert Redfield. A continuación, se inscribió en la Maestría de la Escuela Nacional de Antropología (UNAM) y fue invitado a participar 
de una investigación sobre pueblos indígenas que serían afectados por la construcción de la represa hidroeléctrica de Miguel Alemán, en Oaxaca. A pesar de haber sido contratado para acompañar a los indígenas en su desplazamiento y para convencerlos de que eso sería algo positivo para ellos, rápidamente se colocó al lado de los indígenas, alineándose en una posición contraria al indigenismo de corte asimilacionista que pregonaba por la "integración nacional" (Stavenhagen, 1953). Poco después, Stavenhagen conoció a González Casanova como su profesor en la UNAM. En 1958, al concluir su maestría, González Casanova lo invitó a dictar clases en esta misma casa. ${ }^{11}$ En 1959, Stavenhagen comenzó su doctorado en París y estimulado por su director de tesis, Georges Balandier, realizó lecturas sobre la formación del Estado nacional francés que, para consolidarse, llevó a la colonización del centro sobre las unidades periféricas de la comunidad política. Estas lecturas incluían trabajos del propio Balandier sobre las relaciones interétnicas y estructuras de clase en África, que le marcaron y le influenciaron.

Si bien su trayectoria ayuda a explicar el énfasis que Stavenhagen dio a la etnicidad y a la dimensión del conflicto en la construcción del concepto, su inmersión en las redes intelectuales vinculadas al CLAPCS le hizo profundizar todavía más este interés. A diferencia de González Casanova, que llegó a trabajar más directamente con Costa Pinto desde el momento inicial del CLAPCS, Stavenhagen estableció una relación más cercana con el segundo director del Centro, Manuel Diégues Jr., que tenía un marcado interés por la antropología. Asimismo, desde el momento en el que Stavenhagen llega a Río de Janeiro para asumir la Secretaría General, las preguntas de tipo antropológico y sobre etnicidad eran parte cotidiana de las investigaciones y de los abordajes teóricos que daban vida al Centro.

De igual forma, es importante subrayar que el Plan de Trabajo del CLAPCS aprobado para los años 1963-1964 fue conjuntamente preparado entre Diégues Jr. y Stavenhagen ${ }^{12}$. A diferencia de cómo se hacía en el periodo previo, propusieron elegir un tema central que estructurara las actividades e investigaciones del Centro. El tema establecido, "Estructuras Agrarias y Urbanas de América Latina", definió entre sus ejes prioritarios estudios sobre las condiciones de los grupos indígenas, mediante la identificación de situaciones de conflicto, procesos de integración, destribalización, participación en las sociedades nacionales y sus relaciones con los cambios de las estructuras agrarias, de la urbanización, y de la industrialización (América Latina, 1963: 109-111). Además, el Plan reservó un espacio específico para las investigaciones que Stavenhagen estaba llevando a cabo. La presentación del mismo aclaró que: 
El "staff" del CENTRO estudiará también la posibilidad de realizar un estudio sobre la integración de las poblaciones indígenas en Guatemala, en colaboración con el Instituto Universitario Centroamericano de Investigaciones Económicas y Sociales (Revista América Latina, año 6, №1, 1963: 111)

Ahora bien, este énfasis en la cuestión indígena y en las relaciones de conflictividad no se debía sólo a una "imposición" de la agenda de los mexicanos o, en otras palabras, de afuera hacia adentro. Fue, más bien, fruto de una fértil convergencia entre trayectorias, redes e intereses. En el caso de Río de Janeiro, además del espacio abierto por Diégues Jr., jugó un papel crucial el antropólogo Roberto Cardoso de Oliveira, quien en 1958 ingresó como investigador del Museo Nacional de la Universidad Federal de Río de Janeiro, convirtiéndose en uno de los principales impulsores de la profesionalización de la antropología en Brasil. Su incorporación a dicha institución se dió tras una formación inicial en filosofía en la Universidad de São Paulo, donde se graduó en 1953 y conoció a quien una década después sería su director de tesis doctoral, Florestan Fernandes (Correa y Laraia, 1992). Allí también fue compañero de Fernando Henrique Cardoso y de Octavio Ianni, con quienes mantuvo una relación académica y personal estrecha. Otro dato apreciable en su trayectoria formativa fue la relación con Darcy Ribeiro, quien lo incorporó al trabajo en el Servicio Nacional de Protección del Indio (SPI) entre 1954 y 1957 y lo inició en la antropología (Álvarez, 2010: 170; Amorim, 2001).

En 1958, cuando el CLAPCS fue invitado a integrarse al núcleo de planeamiento censitario del Instituto Brasileño de Geografía y Estadística (IBGE), sus miembros propusieron invitar al Director de la División de Antropología del Museo Nacional, Luís de Castro Faria, a formar parte del núcleo. Argumentaron entonces que él podría "hacer importantes aportes a las cuestiones referentes a la composición étnica de la población brasileña" (Boletín del CLAPCS, año 1, nº 2, 1958: 30). Es así como Castro Faria, quien acabara de llevar a Cardoso de Oliveira al Museo, también lo introdujo en el CLAPCS. Un año después, en 1959, Cardoso de Oliveira ya actuaría como coordinador de un estudio piloto que se profundizaría con la investigación "Estudio de las áreas de fricción interétnica de Brasil", llevado a cabo en el marco de la División de Antropología del Museo Nacional con el auspicio del CLAPCS. El proyecto, cuya duración prevista era de dos años, ganó centralidad en la agenda de investigaciones del Centro y los números de la revista América Latina acompañaron su desarrollo (América Latina, $\mathrm{n}^{\circ}$ 3, año 5, 1962). El proyecto involucró a otros investigadores y propuso un trabajo de campo con el pueblo Tikuna (en el Alto Solimões), a cargo del 
propio Cardoso de Oliveira; los pueblos Akáwa-Asurini, Suruí y Gaviões (en el bajo y medio Tocantins), a cargo de Roberto da Matta; y los pueblos Krahô y Xerênte (en el norte del estado de Goias y sur de Maranhão) a cargo de Roque de Barros Larraia, Maybury-Lewis y Julio Cesar Melatti (Cardoso de Oliveira, 1964; Barros Larraia, 2008).

Fue en el seno de ese proyecto que Cardoso de Oliveira acuñó el concepto de fricción interétnica, noción que se volvería central en sus trabajos posteriores (Amorim, 2001: 46) y referencia obligada en los estudios sobre etnicidad. Las ideas directrices de este concepto son: a) que las sociedades indígenas mantienen con la sociedad "envolvente" (nacional o colonial) relaciones de oposición histórica y estructuralmente demostrables; y b) que la situación de fricción interétnica es una "totalidad sincrética" de poblaciones dialécticamente "unificadas" a través de intereses diametralmente opuestos, aunque interdependientes (Cardoso de Oliveira, 1962: 86).

Como todo concepto, el de fricción interétnica mantiene herencias, líneas de contacto e inspiraciones con multiplicidad de tradiciones y redes de intercambio intelectual. Su elaboración se inspiró en el concepto de "situación colonial", desarrollado por Balandier en los años 1950 (Balandier, 1951). Además, según Cardoso de Oliveira (2004), el concepto se emparentaba también con el de "regiones de refugio", desarrollado unos años después por otro destacado antropólogo mexicano, Gonzalo Aguirre Beltrán, quien también participara de algunas actividades del CLAPCS (Aguirre Beltrán, 1967) ${ }^{13}$. Pero al instalar la pregunta sobre las relaciones entre "la sociedad tribal" y "la sociedad nacional", el concepto de fricción interétnica avanzó más que otros en términos de procesos conflictivos y situaciones de contacto cargadas de historicidad. Se trató de un abordaje "etno-sociológico" (Cardoso de Oliveira, 1962: 87) que se distanció tanto de la antropología funcionalista inglesa (ligada a perspectivas más estáticas del cambio social) como de la antropología culturalista norteamericana (atrapada en los análisis en términos de "aculturación"), por entonces generalizada en el campo antropológico brasileño (Amorim, 2001). En términos del propio Cardoso de Oliveira, el concepto de fricción interétnica se define como el:

contacto entre grupos tribales y segmentos de la sociedad brasileña, caracterizados por sus aspectos competitivos y, la mayoría de las veces, conflictivos, asumiendo ese contacto proporciones 'totales', esto es, envolviendo toda la conducta tribal y no tribal que pasa a ser moldeada por la situación de fricción interétnica (Cardoso de Oliveira, 1962: 86). 
De manera paralela a esta investigación, Cardoso de Oliveira emprende, junto a Luiz de Castro Faria, un amplio proceso de formación de investigadores en el Museo Nacional, inicialmente con cursos de especialidad. Según Barros Larraia (2008: 16) "la propia elección del título del curso que Cardoso de Oliveira dio en el Museo Nacional en 1961, Antropología Social, en lugar de Antropología Cultural, constituyó un desafío. La acusación más frecuente era la de que se trataba de un curso de sociología". Las tensiones alrededor de las delimitaciones disciplinares eran fuertes, pero ello no impidió proficuos diálogos interdisciplinarios. Años después, la ampliación de la propuesta formativa, las articulaciones de David Maybury-Lewis y el apoyo financiero de la Fundación Ford llevarían a la creación, en 1968, del Programa de Posgrado en Antropología Social (PPGAS) de esta institución, del cual Roberto Cardoso de Oliveira fue su primer director (Garcia, 2009) ${ }^{14}$. La proximidad entre el Museo Nacional y el CLAPCS era tal que algunos de sus cursos de antropología no se realizaron en la Quinta da Boa Vista, sede del Museo, sino en la sede del Centro Latinoamericano. ${ }^{15}$

Posteriormente, Cardoso de Oliveira coordinó los proyectos "Estudio del 'Colonialismo Interno' en Brasil" y “Estructura y Dinámica de los Sistemas Interétnicos" (Corrêa y Laraia, 1992). Ambos dialogaban directamente con el trabajo de González Casanova y Stavenhagen, pero también con los últimos avances de la antropología en América Latina. En estos encuentros, como observó Cardoso de Oliveira, el bagaje de reflexión de los autores mexicanos se vio enriquecido a partir del momento en que ambos -pero muy especialmente Stavenhagen-pasaron a conocer las investigaciones de antropólogos brasileños (Cardoso de Oliveira, 1962; Stavenhagen, 1964). Otávio Velho, quien ingresara en el CLAPCS en 1964 como investigador asistente de Diegues Jr. -su ex profesor en la PUC-Rio-, trabajó con Cardoso de Oliveira en el proyecto sobre colonialismo interno (Velho, 2008). Según relato de Otavio Velho, su encuentro con Cardoso de Oliveira en el CLAPCS fue decisivo para que luego ingresara en el PPGAS del Museo Nacional y concluyera bajo su dirección, a principios de 1970, la primera tesis de maestría del recién creado programa de posgrado (Teixeira et al., 2010). Poco después, Cardoso de Oliveira dejaría Río de Janeiro, asentándose en la Universidad de Brasilia donde también contribuyó a crear su programa de posgrado en Antropología Social. El CLAPCS, a su vez, ya entraba en otra etapa, con pocos recursos, menos circulación internacional y menor presencia en el debate latinoamericano. 


\section{Inflexiones, revisiones y reformulaciones}

El concepto de fricción interétnica es "solidario con la noción de colonialismo interno", tal como reconoció el propio Cardoso de Oliveira (2004: 44). Sin embargo, son varias las formas a través de las cuales podemos entender la relación entre los dos conceptos. Amorim (2001: 46) sugiere que fue en las "Siete tesis equivocadas de América Latina" (Stavenhagen, 1965) donde esa conexión se presentó más claramente. A nuestro juicio, en cambio, ello ya se puede vislumbrar en los textos antes discutidos que Cardoso de Oliveira, González Casanova y Stavenhagen publicaron entre 1962 y 1964. En ellos puede notarse que los pasos que Cardoso de Oliveira dio en torno del concepto de fricción interétnica enriquecieron significativamente las reflexiones sobre el colonialismo interno. Esta idea es ratificada por los propios recuerdos de Stavenhagen cuando dice que "en aquellos años" en que vivió en Rio de Janeiro, el concepto de fricción interétnica "llamó mucho su atención" (Lima et.al., 2010).

De igual manera, González Casanova reivindicó, en diferentes momentos, el concepto de fricción interétnica por su capacidad para mostrar "formas de explotación conjunta de la[s] población[es] indígena[s] por las distintas clases sociales de la población [no indígena]" (1965b: 186). A su vez, Cardoso de Oliveira llegó incluso a publicar un artículo específicamente centrado en alegar que la etnología "podría enriquecer su esquema teórico de referencia" si tomara prestada de la "Sociología del subdesarrollo" la noción de colonialismo interno (Cardoso de Oliveira, 1972 [1966]: 83).

Ambos conceptos mantienen entre sí fuertes convergencias teóricas y epistémicas. En primer lugar, subrayan la dimensión política de las relaciones interétnicas y sitúan la reflexión sobre lo particular de un grupo étnico en el marco amplio de sus relaciones con la sociedad que lo abarca. En segundo lugar, incorporan el conflicto como categoría central para pensar las relaciones interétnicas y proponen un entendimiento sociológico y político de los fenómenos culturales ${ }^{16}$. En tercer lugar, en ambos puede verse una comprensión de la etnicidad subalternizada como el resultado del funcionamiento de una estructura de desigualdades, ligada al desarrollo del mercado, las políticas de los gobiernos y las dinámicas de integración nacional.

Antes que resultado de otra casualidad, la publicación en el mismo número de América Latina del "texto inaugural" de González Casanova y del artículo "Aculturação e Fricção Interétnica" de Cardoso de Oliveira, expresan el resultado de un diálogo latinoamericano en el CLAPCS que, aunque partiendo de premisas diferentes, construyó aproximaciones 
convergentes. Por ejemplo: una de las ideas fuerza principales del texto de Cardoso de Oliveira sostenía que el estudio de las relaciones interétnicas tendría mejores resultados si, en lugar de concentrarse en estudiar solamente "las sociedades tribales" analizase de forma simultánea e interrelacionada a la sociedad nacional. Tal idea, como vimos, era insistentemente sostenida por Stavenhagen.

Habiendo nacido de la inquietud por entender la denominada "condición dual" de las sociedades "subdesarrolladas", el concepto de colonialismo interno se destacó por encontrar formas creativas de trascender esta partición conceptual. En ese movimiento, la formulación original, por momentos algo confusa y atrapada en debates sobre la marginalidad, la integración y la homogeneización (González Casanova, 1962), pasó a especificarse a partir de miradas más críticas y sensibles a la dimensión estructural de las relaciones de clases. La dimensión política y económica que el concepto de fricción interétnica interpuso al estudio de las relaciones interétnicas, parece haber dejado su sello en el modo en que Stavenhagen entendió el colonialismo interno. En el concepto de fricción interétnica, las situaciones de los grupos étnicamente diferenciados son leídas como el resultado de sus relaciones con la sociedad envolvente, nacional y/o hegemónica. Este mismo planteo es el que Stavenhagen utilizaría para avanzar en sus estudios sobre las relaciones entre indígenas y ladinos en México y Guatemala. A partir de allí, elaboraría también las críticas más sagaces al concepto de colonialismo interno tal como González Casanova lo había planteado hasta el momento.

Tal como lo haría Frank poco después y de forma más amplia (Frank, 1967), Stavenhagen (1965) planteó que la tesis de que las sociedades latinoamericanas eran "duales" necesitaba ser revisada, pues las llamadas "sociedad civilizada" y "sociedad arcaica" son "dos polos (...) de un único proceso histórico (...) representan el funcionamiento de una sola sociedad global" (Stavenhagen, 1965: 2). En ese sentido, señaló que "las regiones atrasadas [proveedoras de mano de obra barata] desempeñan una función específica en la sociedad nacional y no son meramente zonas a las que, por una razón u otra, no ha llegado el desarrollo" (Stavenhagen, 1965: 3). A partir de allí, Stavenhagen puso en cuestión de manera más directa la condición de "obstáculos al desarrollo" de los sectores "arcaicos" y/o "atrasados". Al respecto señaló que en América Latina, el crecimiento del mercado interno no funciona como "fuerza motriz de la burguesía latinoamericana". En su lugar,

zonas como Lima, Sao Paulo, Santiago y la ciudad de México pueden crecer económicamente por tiempo indefinido, sin que ello implique necesariamente cambios profundos de estructura de las zonas rurales atrasadas, de las "colonias 
internas". Por el contrario, el crecimiento de las zonas modernas es posible justamente debido a la actual estructura social y económica en las zonas atrasadas (Stavenhagen, 1965: 5).

González Casanova no tardó en aceptar estas críticas (Torres Guillen, 2017: 6); y admitió que la idea de "sociedades duales" siempre tuvo en sus textos un sentido más descriptivo que explicativo. Pero lejos de dejar de lado el concepto de colonialismo interno, la crítica que Stavenhagen postuló en 1965 se orientaba a profundizar aún más su capacidad analítica. De hecho, él se valió de ese mismo concepto al postular cada una de sus "siete tesis" para acabar sosteniendo que "en vez de plantear la situación en los países de América Latina en términos de 'sociedad dual' convendría más plantearla en términos de colonialismo interno" (Stavenhagen, 1965: 3).

En el mismo año de la publicación de sus conocidas Siete Tesis, Stavenhagen defendía su tesis doctoral, publicada en 1969 como Las clases sociales en las sociedades agrarias. Aunque defendida en Francia, fue elaborada en buena medida durante su estancia en Río de Janeiro. Como consecuencia, se puede observar varios rastros del debate clapcsiano en este que fue uno de sus más importantes libros. Ya en las primeras páginas, Stavenhagen recuperaba los planteos que Jacques Lambert hiciera en el seminario Resistência à Mudança, de 1959 (Stavenhagen, 1969: 48). Pero tras reconocer que el problema del "dualismo es particularmente agudo", enfatizaba que "el sector arcaico de la llamada sociedad dual es el subproducto, justamente, de un cierto desarrollo económico localizado y limitado regionalmente" (Stavenhagen, 1969: 48).

También vale registrar que los avances de lo que acabara siendo el capítulo 16 del libro habían sido originalmente publicados en la revista América Latina en 1963. Allí Stavenhagen enfatizaba la necesidad de distanciarse de la antropología culturalista norteamericana para poder entender la realidad de las "poblaciones indígenas" de América; y adentrarse entonces en la reflexión sobre la estructura económica, las clases sociales y las relaciones de poder. Como puede verse, se trataba de un enfoque notoriamente impregnado por la sociología y la antropología crítica desplegada en el proceso de maduración del espacio clapcsiano. 


\section{Conclusiones}

El diálogo intelectual entre Roberto Cardoso de Oliveira, Pablo González Casanova y Rodolfo Stavenhagen engendró uno de los debates más fecundos y originales de las ciencias sociales latinoamericanas. Durante varios años, y muy especialmente entre 1959 y 1965, construyeron y difundieron el concepto de colonialismo interno en América Latina, mientras convergieron y participaron en el CLAPCS. Todos ellos tuvieron diferentes formas de anclaje e inserción en el Centro, desde los más altos puestos directivos, con capacidad deliberativa y ejecutiva sobre decisiones relevantes, a la coordinación y dinamización de actividades y proyectos de investigación. Stavenhagen recordaba que Cardoso de Oliveira "siempre [le] mandaba sus escritos" (Lima et.al., 2010) y discutían sobre los diferentes aspectos y los contextos de aplicación de cada uno de los conceptos. Los múltiples agradecimientos cruzados que aparecen en los artículos que Cardoso de Oliveira, González Casanova y Stavenhagen publicaron en América Latina también dan cuenta de la importancia que cada uno tuvo para el otro.

Sin menospreciar el papel que cada autor ha jugado en la gestación del debate del colonialismo interno, hemos mostrado en el presente artículo que su construcción fue el resultado de una dinámica colectiva, transnacional e interdisciplinar. Las redes intelectuales del CLAPCS y la agenda teóricopolítica del momento fueron fundamentales. De los debates e investigaciones sobre las "resistencias al cambio", el "progreso" y la "etnicidad", fuertemente presentes en el Centro a finales de los 1950 e inicio de los 1960, surgieron agendas, preguntas y diálogos que estimularon a Cardoso de Oliveira, González Casanova y Stavenhagen a superar lo que aparecía como la condición "dual" de las sociedades "subdesarrolladas".

Las contribuciones críticas que los debates sobre el colonialismo interno hicieron a las teorías de la modernización fueron imprescindibles para generar un momento inicial de transición entre una sociología del desarrollo impregnada de un imaginario modernizador a una sociología crítica. De hecho, Frank (1973) reconoce que las teorías del colonialismo interno fueron fundamentales para el surgimiento posterior de la teoría de la dependencia. Podríamos quizás, incluso, ir más allá y afirmar que el debate sobre el colonialismo interno no sólo contribuye a gestar la teoría de la dependencia, sino que también permitió, casi dos décadas después, identificar algunas de sus limitaciones.

Eso se refleja especialmente en el trabajo de Jean Casimir, sucesor de Stavenhagen como Secretario General del CLAPCS y uno de los más destacados intelectuales contemporáneos de Haití y del Caribe. 
Cuando Casimir llegó a Río de Janeiro en 1965, no venía de Haití, sino de México, donde se formó en la UNAM y fue bastante influenciado por González Casanova. Al llegar al CLAPCS conoció las contribuciones de Cardoso de Oliveira y de Stavenhagen, aunque su formulación es muy tributaria también del estrecho diálogo con la pareja de intelectuales haitianos, Suzy Castor y Gérard Pierre-Charles (León y Voltaire, 2018) y los trabajos de Franz Fanon. Si bien Casimir publicó cinco artículos en la revista América Latina y es desde entonces un referente importante en la construcción de vínculos entre el pensamiento social latinoamericano y caribeño, fue sólo en 1980 cuando publicó su trabajo más influyente: La cultura oprimida. Uno de sus principales méritos fue pensar el colonialismo interno no a través de sus expresiones específicas (lo indígena, lo negro, lo andino, etc.), sino a partir de una perspectiva más procesual y multi-escalar. Esto fue posible, sin dudas, debido a los avances de la teoría de la dependencia, pero también a una relectura creativa de Mariátegui y de los trabajos iniciales de González Casanova y Stavenhagen a partir de quienes busca explicar, para el caso haitiano, las estructuras y las relaciones coloniales, los actores y sus ideologías. Los fundamentos históricos e ideológicos del colonialismo interno en Haití son brillantemente analizados por Casimir quien cierra, de alguna manera, el debate de "matriz clapcsiana" sobre el tema, con una crítica a determinadas perspectivas de la dependencia demasiado estadocéntricas y herméticas.

A partir de entonces, proliferaron otras voces y miradas sobre el colonialismo interno y la "colonialidad", sea en los brillantes trabajos de Silvia Rivera Cusicanqui o en las múltiples derivaciones del pensamiento postcolonial y decolonial de las últimas décadas (Cesarino, 2017; Martins, 2018). Curiosamente, sin embargo, éstos no suelen nacer a partir del CLAPCS ni tampoco contra el CLAPCS, sino a pesar del Centro, mostrando un "déficit de acumulación" (Svampa, 2016) o una discontinuidad, especialmente fuerte a partir de los años 1980, en el pensamiento crítico latinoamericano.

Recebido em 28 de agosto de 2020

Aprovado em 29 de abril de 2021 
Breno Bringel: Doctor por la Universidad Complutense de Madrid. Profesor del Instituto de Estudios Sociales y Políticos de la Universidad del Estado de Río de Janeiro, investigador del CNPq y coordinador del Núcleo de Teoría Social y América Latina. Es presidente del Research Committee on Social Classes and Social Movements de la International Sociological Association y directivo de la Asociación Latinoamericana de Sociología. Autor de una centena de artículos y de una decena de libros, incluyendo Alerta Global (2020) y Critical Geopolitics and Regional (Re)Configurations (2019). Sus trabajos recientes examinan las transformaciones del activismo contemporáneo y la construcción teórica/ geopolítica del pensamiento latinoamericano.

https://orcid.org/0000-0002-6961-310X

E-mail: brenobringel@iesp.uerj.br

Miguel Leone: Doctor en Ciencias Sociales por la Universidad Nacional de General Sarmiento y el Instituto de Desarrollo Económico y Social. Docente y Becario Posdoctoral de la Universidad de Buenos Aires y docente de la Universidad Nacional de Rosario. Dirige el proyecto PICT (2019-2021) "Indígenas, iglesias y partidos políticos en Formosa y Chaco". Es autor del libro En el nombre del otro. Cristianismo y pueblos indígenas en la región chaqueña argentina (1965-1994) y ha publicado una veintena de artículos en revistas académicas internacionales. Sus áreas de trabajo son la sociología y la historia latinoamericana y sus investigaciones se centran en los movimientos sociales y en el movimiento indígena en Abya Yala.

https://orcid.org/0000-0002-1618-6968

E-mail: miguel.leone.j@gmail.com 


\section{Nota}

1 Este artículo es parte de una investigación más amplia, coordinada por Breno Bringel, sobre la experiencia del Centro Latinoamericano de Pesquisas en Ciencias Sociales (CLAPCS) que ha contado desde 2014 con financiación de la FAPERJ (JCNE), del Programa Prociencia - UERJ y del Madrid Institute for Advanced Study (MIAS). Además de los autores de este texto, el equipo de investigación cuenta con Pedro Blois, Leonardo Nóbrega, Lilia Macedo Silva y Felipe Macedo, a quienes agradecemos por el trabajo conjunto. Por sus pertinentes comentarios y sugerencias a este texto agradecemos también a dos revisoras/es anónimos de Mana y a Antonio Carlos de Souza Lima, Carlo Baghetti, Jaime Torres Guillén, Paulo Henrique Martins y Waldo Ansaldi. Aunque no comentaron esta versión, agradecemos igualmente a Afrânio Garcia Jr., Alexis Cortés, Antonio Brasil Jr., Fernanda Beigel, José Maurício Domingues y Otávio Velho por la lectura de otros fragmentos y por el diálogo permanente sobre el proyecto.

2 La distinción entre el "uso político" y el "uso analítico" de la noción de colonialismo interno merecería mayor atención en estudios futuros sobre el tema. Un camino promisorio sería rastrear las diferentes genealogías y apropiaciones del concepto en contextos culturales, geográficos, históricos y políticos diferentes, buscando identificar las similitudes y las especificidades, bien como las omisiones y las tensiones entre el debate académico de las últimas décadas y la discusión política e intelectual más amplia sobre el colonialismo interno. En esta línea, el texto reciente de Iborra-Mallent y Montañez-Pico (2020) abre discusiones relevantes al ubicar el rol pionero del comunista afroamericano Harry Haywood y los silencios posteriores sobre su trayectoria y obra en el pensamiento crítico latinoamericano.

3 El primero fue una obra que alcanzó especial fama, convirtiéndose rápidamente en un clásico de las ciencias sociales latinoamericanas. Los tres mil ejemplares de su primera edición se agotaron en pocos meses y a lo largo de la siguiente década fue reeditado seis veces, además de traducido al alemán, francés, inglés y portugués. Algo parecido ocurrió con el segundo libro, que también se difundió muy ampliamente, llegando a su onceava edición en 1987.

4 Fueron los casos de Gino Germani (Argentina), Orlando Carvalho (Brasil), Humberto Diez Contreras (Chile), Rafael Arboleda (Colombia), Oscar Chavez Esquivel (Costa Rica), Pablo González Casanova (México) y José Luis Salcedo-Bastardo (Venezuela).

5 El CLACSO fue creado tras la realización de la Segunda Conferencia de Centros e Institutos Latinoamericanos de Investigación del Desarrollo, celebrada en Bogotá en octubre de 1967. El CLAPCS se involucró desde su primer momento (ya en 1964 a través de la Conferencia de Sociología Comparativa de Buenos Aires) en el proceso de construcción y consultas sobre la creación de este nuevo centro que tendría una función de agregación regional, en el sentido de aproximar los diferentes institutos y científicos de ciencias sociales de la región, contribuyendo a integrarlas. 
En abril de 1968 el CLAPCS publicó en su revista América Latina (año 11, n.2) un número especial con todos los documentos relativos a la institucionalización y la creación de CLACSO.

6 Entre los experts que pasaron más tiempo en el CLAPCS figuraron también Jean Labbens, Jacques Lambert, Bertram Hutchinson, Benno Galjart, Jean Pierre Bombard, Sugiyama Yutaka, Jean Casimir y Torcuato di Tella.

7 Este proyecto encargado a Herbert Blumer, contó con el apoyo de la demógrafa Anita Hirsh, y se presentaba como una ampliación del trabajo del propio Costa Pinto (1958), que resultó en la primera publicación del CLAPCS.

8 Tras su pasaje por el CLAPCS, Kahl siguió colaborando a distancia en algunas actividades del Centro, participando incluso de encuentros importantes posteriores como la Conferencia Internacional sobre Investigación Comparativa, realizada en Buenos Aires en septiembre de 1964. Presidida por Manuel Diégues Jr., ésta también contó con la participación de Peter Heintz, Glaucio Soares, Pablo González Casanova, Aldo Solari, Jorge Graciarena, Torcuato di Tella, Johan Galtung, Alain Touraine, Alessandro Pizzorno, Irving Louis Horowitz, entre otros.

9 Además de Mills, otro investigador que influenció bastante el debate inicial sobre el colonialismo interno y a los investigadores del CLAPCS fue el economista sueco Gunnar Myrdall. En su libro Economic Theory and Underdeveloped Regions (1957), Myrdall señaló referencias bastante parecidas a las que Mills subrayaría luego en el Seminario de 1959, pero vinculándolas explícitamente a la dimensión étnica y religiosa.

10 Véase el conversatorio entre Pablo González Casanova y Rodolfo Stavenhagen en el acto conmemorativo del quincuagésimo aniversario de las Siete Tesis Equivocadas en América Latina, Colegio de México, junio de 2015 (disponible en: https://www.youtube.com/watch?v=5Brw74WU1YU). Si bien Stavenhagen tenía en aquel momento influencia en la revista América Latina por ser Secretario General del CLAPCS, no fue el editor o el director de la Revista, tal como sugiere Gandarilla (2018).

11 A propósito de esos años, José Luis Reyna, profesor del COLMEX, recuerda que en 1959 fue alumno de Stavenhagen en un seminario, según él, "memorable" donde se dedicaron a discutir tres obras: El Capital ( 2 a edición revisada y corregida, FCE) de Marx, La Rebelión de las Masas de Ortega y Gasset y El Príncipe de Maquiavelo (Exposición de José Luis Reyna en la conmemoración de los 40 años del Centro de Estudios Sociológicos (CES) de México realizada el 5 y 6 de abril de 2013).

12 Sobre la relación entre Diégues Jr. y Stavenhagen véase también Grisendi (2014: 161-163).

13 En aquel momento, las tensiones entre el conservacionismo étnico y su asimilación a la cultura impuesta de lo mestizo, o entre la perspectiva del Estado y voces más críticas que empiezan a emerger tienen ecos profundos en las disputas epistémicas, teóricas y paradigmáticas sobre la interpretación de lo rural en México (Hewitt, 1988). 
14 El liderazgo de Cardoso de Oliveira en la construcción institucional de la antropología social en Brasil incluyó su participación en varios comités directivos de la Asociación Brasileña de Antropología (ABA) durante los años 1950 y 1960. Asimismo, luego sería elegido presidente de la ABA (1984-1986), vice-presidente de la IUAES (International Union Of Anthropological And Ethnological Sciences - IUAES (1988-1993) y presidente de la Asociación Latinoamericana de Antropología - ALA (1993-1997).

15 El noticiario del primer número de la revista América Latina de 1969 menciona la firma de un convenio entre el CLAPCS y la División de Antropología del Museo Nacional de la UFRJ para "utilizar seu espaço físico, biblioteca e recursos técnicos". Varios de nuestros entrevistados en la investigación ratifican que eso ocurrió.

16 Aun así, el propio Cardoso de Oliveira señalaba que el objetivo no era reducir la cultura a un epifenómeno, es decir, a algo vacío de significación. Cardoso nunca dejó de reconocer en la cultura una dimensión de lo real que merece ser explorada. Sus salvedades apuntaron a evitar un punto de vista culturalista que suele tener dificultades para explicar las estructuras operantes en todo "contacto" interétnico (Cardoso de Oliveira, 1963: 39). 


\section{Referencias}

ADAM, Heribert. 1972. Modernizing Racial Domination: The Dynamics of South African Politics. Berkeley: University of California Press.

AGUIAR, Neuma. 2001. "A contribuição dos métodos quantitativos para a análise dos processos de estratificação e mobilidade social no Brasil". In: XXV Encontro Anual da ANPOCS, Caxambu.

AGUIRRE BELTRÁN, Gonzalo. 1967. Regiones de Refugio: El Desarrollo de la Comunidad y el Proceso Dominical en Mestizo América. México: Instituto Indigenista Interamericano.

ALLEN, Robert. 2015. "Reassessing the internal (neo)colonialism theory", The Black Scholar: Journal of Black Studies and Research, v.35, n.1, 2-11.

AMIN, Samir. 2009. El socialismo en el siglo XXI. Reconstruir la perspectiva socialista. Madrid: IEPALA.

AMORIM, Maria Stella de. 2001. Roberto Cardoso de Oliveira, um artífice da antropologia. Brasília: Paralelo 15.

BALANDIER, Georges. 1951. "La Situation Coloniale: Approche Théorique," Cahiers Internationaux de Sociologie, n.9, 44-79.

BARROS LARAIA, Roque de. 2008. "Roberto Cardoso de Oliveira, antropólogo e educador", Anuário Antropológico, v.33, n.1, 13-26.

BEIGEL, Fernanda. 2009. "La Flacso chilena y la regionalización de las ciencias sociales en América Latina (1957-1973)", Revista Mexicana de Sociología, v.71, n.2, 319-349. . 2016. "El nuevo carácter de la dependencia intelectual", Cuestiones de Sociología, n.14, e004, 1-17.

BLAUNER, Robert. 1969. "Internal Colonialism and Ghetto Revolt", Social Problems, v.16, n.4, 393-408.
BLUMER, Herbert. 1959. "The study of urbanization and industrialization methodological deficiences", Boletim, CLAPCS, año 2, n.2, 17-34.

BOLETÍN DEL CENTRO LATINOAMERICANO DE PESQUISA EM CIÊNCIAS SOCIAIS. 1958. Rio de Janeiro: CLAPCS, Año 1, Números 1 y 2 (marzo y septiembre).

BOLETÍN DEL CENTRO LATINOAMERICANO DE PESQUISA EM CIÊNCIAS SOCIAIS. 1959. Rio de Janeiro: CLAPCS, Año 2, Números 1, 2, 3 y 4 (marzo, mayo, julio y noviembre).

BOLETÍN DEL CENTRO LATINOAMERICANO DE PESQUISA EM CIÊNCIAS SOCIAIS. 1960. Rio de Janeiro: CLAPCS, Año 3, Números 1, 2, 3 y 4 (febrero, mayo, agosto y noviembre).

BRASIL JR., Antonio. 2013. Passagens para a teoria sociológica: Florestan Fernandes e Gino Germani. São Paulo: Hucitec.

BRINGEL, Breno et al. 2015. "Notas sobre o CLAPCS na 'era Costa Pinto' (1957- 1961): construção institucional, circulação intelectual e pesquisas sobre a América Latina no Brasil". In: Breno Bringel y José Mauricio Domingues (Coords.) Sociologia Latino-americana II: desenvolvimento e atualidade, Dossiê Temático, n.5, Núcleo de Estudos de Teoria Social e América Latina, Rio de Janeiro, 10-18.

BRINGEL, Breno; DOMINGUES, José Maurício. 2015. "Teoria social, extroversão e autonomia: impasses e horizontes da sociologia (semi) periférica contemporânea", Caderno CRH, v.28, n.73, 59-76. 
BRINGEL, Breno; MALDONADO, Emiliano. 2016. "Pensamento crítico latino-americano e pesquisa militante em Orlando Fals Borda: práxis, subversão e libertação", Revista Direito \& Práxis, v.7, n.13, 389-413.

BRINGEL, Breno; ECHART, Enara. 2017. "Imaginarios sobre el desarrollo en América Latina: entre la emancipación y la adaptación al capitalismo", Revista Española de Desarrrollo y Cooperación, n.39, 9-24.

BROUÉ, Pierre. 1977. Histoire de l'internationale communiste (19191943). Paris: Fayard.

BURAWOY, Michael. 1974. "Race, class and colonialism", Social and Economic Studies, v.23, n.4, 521-550.

CARDOSO DE OLIVEIRA, Roberto. 1962. "Projeto: "Estudo de áreas de fricção interétnica no Brasil", Revista América Latina, Rio de Janeiro, ano 5, n.2, 5-90.

. 1963. "Aculturação e fricção interétnica", Revista América Latina, Centro Latino-americano de Pesquisas em Ciências Sociais, Rio de Janeiro, ano 6, n.3, 15-32.

- 1964. O Índio e o Mundo dos Brancos. A Situação dos Tukuna do Alto Solimões. Rio de Janeiro: Difel. 1972 [1966]. "A Noção de 'Colonialismo Interno' na Etnologia". En: Roberto Cardoso de Oliveira, A Sociologia do Brasil Indígena, Rio de Janeiro: Tempo Brasileiro. São Paulo: Editora da USP, 77-84.

. 2004. "El movimiento de los conceptos en la Antropología". En: Alejandro Grimson, L. Ribeiro y Pablo Seman, La antropologia brasileña contemporánea. Contribuciones para un diálogo latinoamericano. Buenos Aires: Prometeo Libros-ABA, 35-52.

CARTER, G.; KARIS, T; STULTZ, N. 1967. South Africa's Transkei: The
Politics of Domestic Colonialism. Evanston: Northwestern University Press.

CASIMIR, Jean. 1980. La cultura oprimida. México: UNAM.

CASTRO GOMES, Ângela; ARAUJO, Maria Celina, 2008. "Entrevista com Gláucio Ary Dillon Soares", Estudos Históricos, v.21, n. 42, 323-349.

CESARINO， Letícia . 2017 . "Colonialidade interna, cultura e mestiçagem: repensando o conceito de colonialismo interno na antropologia contemporânea", Ilha, v.19, n.2, 73-105.

COSTA PINTO, Luís A. 1958. Recôncavo: Laboratório de uma Experiência Humana. Rio de Janeiro: Centro Latino-americano de Pesquisas em Ciências Sociais.

CORRÊA, Mariza; LARAIA Roque (Orgs.). 1992. Roberto Cardoso de Oliveira : Homenagem. Instituto de Filosofia e Ciências Humanas, Unicamp.

CORTES, Alexis. 2018. Favelados e pobladores nas ciências sociais: a construção teórica de um movimento social. Rio de Janeiro: EdUERJ.

CRUSE, H. 1968. Rebellion or Revolution? New York: William Morrow \& Company, Inc.

DE LA GARZA, Enrique. 2015. “Un breve balance de la sociología en México". En: Breno Bringel y José Mauricio Domingues (Coords.) Sociologia Latino-americana II: desenvolvimento e atualidade, Dossiê Temático, n.5, Núcleo de Estudos de Teoria Social e América Latina, Rio de Janeiro, 37-42.

DOMINGUES， José Maurício; MANEIRO, María. 2004. "Revisitando Germani: a interpretação da modernidade e a teoria da ação", Dados, vol.47, n.4, 643-668. 
FERREIRA, Janaína. 1999. Resistências à Mudança: um debate dos cientistas sociais na década de 50. Dissertação (Mestrado em Sociologia e Antropologia) - Universidade Federal do Rio de Janeiro, Rio de Janeiro.

FRANK, André Gunder. 1967. Capitalismo y subdesarrollo en América Latina. Buenos Aires: Siglo XXI Editores. . 1972. "Economic dependence, class structure, and underdevelopment policy". En: James Cockcroft, André Gunder Frank y Dale Johnson (Eds.) Dependence and Underdevelopment: Latin America's Political Economy. New York: Anchor Books, 19-45. . 1973. América Latina: subdesarrollo y revolución, ERA, México.

GANDARILLA, José. 2018. "Notas sobre la construcción de un instrumento colectivo: el colonialismo interno en la obra de Pablo González Casanova", Pléyade 21, n.21, 141-162.

GARCIA, Afrânio. 2009. "Fundamentos Empíricos da razão antropológica: A criação do PPGAS e a seleção das espécies científicas", Mana, v.15, n.2, 411-447.

GONZÁLEZ CASANOVA, Pablo. 1962. "Sociedad plural y desarrollo: el caso de México", Revista América Latina, Centro Latino-americano de Pesquisas em Ciências Sociais, Rio de Janeiro, año 5, n.4, p.31-52.

1963 a. "Sociedad plural, colonialismo interno y desarrollo", Revista América Latina, Centro Latino-americano de Pesquisas em Ciências Sociais, Rio de Janeiro, ano 6, n.3, 15-32.

. 1963b. "Mexico: Desarrollo y subdesarrollo". Desarrollo Económico, v.3, n.1-2, 285-302.

1965a. "Internal colonialism and national development", Studies in Comparative International Development, v.1, n.4, 27-37.
. 1965b. La democracia en México. México D.F.: Ediciones Era. . 1969. Sociología de la explotación. México D.F.: Siglo XXI. 2006. Colonialismo interno [una redefinición]. En: Atilio A. Boron, Javier Amadeo y Sabrina González (comps.). La teoría marxista hoy: problemas y perspectivas. Buenos Aires: Consejo Latinoamericano de Ciencias Sociales - CLACSO, 409434.

GRISENDI, Ezequiel. 2014. "El Centro de la periferia: internacionalización de las ciencias sociales y redes académicas latinoamericanas", Crítica e Sociedade: Revista de Cultura Política, v.4, n.2, 148-167.

JACKSON, Luiz Carlos; BLANCO, Alejandro. 2016. "O caudilho da sociología mexicana: Pablo González Casanova e A Democracia no México", Tempo Social, v.28, n.3, 117-143.

HAYWOOD, Harry. 1948. Negro Liberation. New York: International Publishers.

HICKS, Jack. 2004. "On the Application of Theories of 'Internal Colonialism' to Inuit Societies". Annual Conference of the Canadian Political Science Association, Winnipeg, June 5.

KAHL, Joseph. 1957. The American Class Structure. Nueva York: Rinehart. . 1962. "Urbanização e Mudanças Ocupacionais no Brasil", Revista América Latina, n.4, 21-30. . 1976. Modernization, exploitation and dependency in Latin America: Germani, González Casanova and Cardoso. New Brunswick: Transaction Books.

KOSELLECK, Reinhart. 2002. The Practice of Conceptual History. Timing History, Spacing Concepts. California: Stanford University Press. 
HECHTER, Michael. 1975. Internal colonialism: The Celtic Fringe in British National Development 1536-1966. Berkeley: University of California Press.

HEWITT, Cynthia. 1988. Imágenes del campo: la interpretación antropológica del México rural. México: El Colegio de Mexico.

IBORRA-MALLENT, Juan Vicente; MONTAÑEZ-PICO, Daniel. 2020. "Los orígenes de la idea de 'colonialismo interno' en el pensamiento crítico del comunista afroamericano Harry Haywwod: crónica de una conversación con Gwendolyn Midlo Hall", Tabula Rasa, Bogotá, n.35, 89-114.

LENIN, V. 1952. [1916] Imperialism, the highest stage of capitalism. Moscow: Foreign Languages Publishing House.

LIMA, Roberto; CABRAL Jr., Vilson A. 2010. "Antropologia, direitos humanos e povos indígenas: entrevista com Rodolfo Stavenhagen". Sociedade e Cultura, v.13, n.1, 137-142.

MARTINS, Paulo Henrique. 2018. "La actualidad de la Teoría del Colonialismo Interno para el debate sobre la dominación y los conflictos inter-étnicos". In: Paulo Henrique Martins, Alberto Bialakowski, Marcelo Arnold-Chatalifaud, Nora Garita e Jaime Preciado (Eds.) Encrucijadas abiertas en América Latina y el Caribe, Tomo II. Buenos Aires: ALAS/CLACSO/Teseo, 311334.

MYRDALL, Gunnar. 1957. Economic Theory and Underdeveloped Regions. New York: Harper Torchbooks.

ROBINSON, Cedric. 1983. Black Marxism. Londres: Zed Books.

OTO, Alejandro de; CATELLI, Laura. 2018. "Sobre colonialismo interno e subjetividade. Notas para um debate". Tabula Rasa, 28, 1-16.
SERRANO, Margarita. 2016. "Los aportes de Lucío Mendieta y Nuñez a la institucionalización de la sociología en México (1939-1951)", Tempo Social, v.28, n.3, 77-94.

STAVENHAGEN, Rodolfo. 1953. "En la cuenca del Papaloapan: aspectos de antropología social aplicada", Tlatoani - Revista del Instituto Nacional de Antropología e Historia de México, n.7.

. 1963. "Clases, colonialismo y aculturación", Revista América Latina, Centro Latino-americano de Pesquisas em Ciências Sociais, Rio de Janeiro, ano 6, n.4, 63-104. . 1964. "Las relaciones interétnicas en algunas áreas de América Indígena", Revista América Latina, Centro Latino-americano de Pesquisas em Ciências Sociais, Rio de Janeiro, ano 7, n.3, 103-108.

. 1965. "Siete Tesis Equivocadas sobre América Latina", El Día, 25 e 26 de junho de 1965.

. 1969. Las clases sociales en las sociedades agrarias. México: Siglo XXI.

SILVA, Leonardo Nóbrega. 2019. Editoras e ciências sociais no Brasil: a Zahar Editores e a emergência das ciências sociais como gênero editorial (1957-1984). Tese de Doutorado em Sociologia (Instituto de Estudos Sociais e Políticos - Universidad do Estado do Rio de Janeiro).

SVAMPA, Maristella. 2016. Debates latinoamericanos: indianismo, desarrollo, dependencia, populismo. Buenos Aires: Edhasa.

TEIXEIRA, Sergio Alves; LEWGOY, Bernardo; STEIL，Carlos Alberto; ECKERT, Cornelia. 2010. "Otávio Velho: trajetória e percurso acadêmico", Horizontes Antropológicos, n.34, 481-506. 
TORRES GUILLÉN, Jaime. 2012. Dialéctica de la imaginación: Pablo González Casanova, una biografía intelectual. Tesis doctoral. Centro de Investigaciones y Estudios Superiores en Antropología Social. . 2017. "La imaginación sociológica de Pablo González Casanova", Revista Mexicana de Sociología, v.79, n.1, 175-200.

VALDÉS, Eduardo Devés. 2003. El pensamiento latinoamericano en el siglo XX: desde la CEPAL al neoliberalismo, 1950-1990. Buenos Aires: Editorial Biblos.

VELHO, Otávio. 2008. "A Terceira Margem de Roberto Cardoso de Oliveira", Mana, v.14, n.2, 555-562.
WRIGHT MILLS, Charles. 1960. "Remarks on the problem of industrial development". In: Anais do Seminário Internacional Resistências às Mudanças - fatores que impedem ou dificultam o desenvolvimento. Rio de Janeiro: Centro Latino- Americano de Pesquisas em Ciências Sociais, 281-287.

ZAPATA, Francisco. 1981. "La innovación sociológica en México: la contribución de Rodolfo Stavenhagen", Ciencia, n.32, 133-146. . 1990. Ideología y política en América Latina. México: Colegio de México. . 1995. "Las Siete Tesis: Treinta Años Después", Estudios Sociológicos, n.37, 181-188. 


\section{LA CONSTRUCCIÓN INTELECTUAL DEL CONCEPTO DE COLONIALISMO INTERNO EN AMÉRICA LATINA: DIÁLOGOS ENTRE CARDOSO DE OLIVEIRA, GONZÁLEZ CASANOVA Y STAVENHAGEN (1959-1965)}

\section{Resumen}

Este artículo argumenta que el debate sobre el colonialismo interno en América Latina es resultado de una dinámica colectiva, transnacional e interdisciplinaria generada a partir de intercambios ocurridos en la confluencia entre la institucionalización de las ciencias sociales de la región y las críticas iniciales al horizonte modernizador imperante. Se reconstruye, a partir de diversas fuentes primarias originales, los diálogos seminales establecidos entre Roberto Cardoso de Oliveira, Pablo González Casanova y Rodolfo Stavenhagen entre finales de 1950 y la primera mitad de 1960 en torno al Centro Latinoamericano de Pesquisas en Ciencias Sociales - CLAPCS. Se propone así una genealogía y un itinerario del concepto de colonialismo interno en el que interactúan contexto, historia y teoría, en una trama de emergencia, construcción y reelaboración de una noción clave para el pensamiento latinoamericano, en sus contactos con otras afines como la de "fricción interétnica".

Palabras clave: Colonialismo interno; Fricción interétnica; CLAPCS; Roberto Cardoso de Oliveira; Pablo González Casanova; Rodolfo Stavehangen.

\author{
A CONSTRUÇÃO INTELECTUAL DO \\ CONCEITO DE COLONIALISMO \\ INTERNO NA AMÉRICA LATINA: \\ DIÁLOGOS ENTRE CARDOSO DE \\ OLIVEIRA, GONZÁLEZ CASANOVA E \\ STA VENHAGEN (1959-1965)
}

\section{Resumo}

Este artigo argumenta que o debate sobre o colonialismo interno na América Latina é fruto de uma dinâmica coletiva, transnacional e interdisciplinar gerada a partir de trocas ocorridas na confluência entre a institucionalização das ciências sociais da região e as primeiras críticas ao horizonte modernizador então dominante. Os diálogos seminais estabelecidos entre Roberto Cardoso de Oliveira, Pablo González Casanova e Rodolfo Stavenhagen, entre o final dos anos 1950 e a primeira metade de 1960 em torno do Centro Latino-Americano de Pesquisas em Ciências Sociais (CLAPCS), são reconstruídos a partir de várias fontes primárias originais. Assim, propõem-se uma genealogia e um itinerário do conceito de colonialismo interno, em que contexto, história e teoria interagem numa trama de emergência, construção e reelaboração de uma noção-chave para o pensamento latinoamericano, em suas interfaces com outros conceitos afins como o de "fricção interétnica".

Palavras-chave: Colonialismo interno; Fricção interétnica; CLAPCS; Roberto Cardoso de Oliveira; Pablo González Casanova; Rodolfo Stavehangen. 
THE INTELLECTUAL CONSTRUCTION

OF THE CONCEPT OF INTERNAL

COLONIALISM IN LATIN AMERICA:

DIALOGUES BETWEEN CARDOSO DE

OLIVEIRA, GONZÁLEZ CASANOVA

AND STAVENHAGEN (1959-1965)

\section{ABSTRACT}

This article argues that the debate on internal colonialism in Latin America is the result of a collective, transnational and interdisciplinary dynamic generated through exchanges that occurred at the confluence between the institutionalization of the region's social sciences and the initial criticisms of the modernization horizon. The seminal dialogues that were established between Roberto Cardoso de Oliveira, Pablo González Casanova and Rodolfo Stavenhagen between the late 1950s and the first half of 1960 around the Latin American Center for Social Sciences Research (CLAPCS) are reconstructed from several original primary sources. Thus, a genealogy and itinerary of the concept of internal colonialism is proposed, in which context, history and theory interact in a plot of emergence, construction and re-elaboration of a key notion for Latin American thought, in its contacts with other related concepts such as that of "inter-ethnic friction".

Keywords: Internal colonialism; Interethnic friction; CLAPCS; Roberto Cardoso de Oliveira; Pablo González Casanova; Rodolfo Stavehangen. 